TITLE: Use of Molecular modeling to determine the interaction and competition of gases within coal for carbon dioxide sequestration

REPORT: Annual Technical Progress Report

REPORTING PERIOD

START DATE: $\quad 09 / 30 / 2003$

\title{
REPORTING PERIOD
}

END DATE: $\quad$ 09/29/2004

AUTHORS: $\quad$ Jeffrey D. Evanseck, Jeffry D. Madura, and Jonathan P. Mathews*

DATE: $\quad$ May 27, 2005

AWARD No.: $\quad$ DE-FG26-02-NT41556

INSTITUTIONS: Duquesne University

Department of Chemistry and Biochemistry

600 Forbes Ave

Pittsburgh, PA 15282

Pennsylvania State University*

126 Hosler Building

Energy \& Geo-Environmental Engineering \&

The Energy Institute

University Park, PA 16802

PHONES: $\quad$ (412) 396-6337 (Evanseck), (814) 863-6213 (Mathews)

FAXES: $\quad$ (412) 396-5683 (Evanseck), (814) 865-3248 (Mathews)

E-MAILS: $\quad$ evanseck@duq.edu and jmathews@psu.edu 


\section{DISCLAIMER}

"This report was prepared as an account of work sponsored by an agency of the United States Government. Neither the United States Government nor any agency thereof, nor any of their employees, makes any warranty, express or implied, or assumes any legal liability or responsibility for the accuracy, completeness, or usefulness of any information, apparatus, product, or process disclosed, or represents that its use would not infringe privately owned rights. Reference herein to any specific commercial product, process, or service by trade name, trademark, manufacturer, or otherwise does not necessarily constitute or imply its endorsement, recommendation, or favoring by the United States Government or any agency thereof. The views and opinions of authors expressed herein do not necessarily state or reflect those of the United States Government or any agency thereof." 


\begin{abstract}
We have made progress in carrying out large scale molecular dynamics simulations using the CHARMM force field in order to refine our coal / guest interactions. There have been two issues facing us over the last year. First, we have had to create a completely new topology and parameter definition for coal. Since we are using a classical force field, we have adopted the strategy of treating coal composed of individual common fragments based upon a distribution of mass, composition, and bonding. Our procedure is similar to treating a protein as being composed of the discrete set of amino acids. Second, we have had to incorporate the quality $\mathrm{CO}_{2}$ parameters that we have developed over the last two years. There are the geometric and arithmetic procedures, which we have successfully implemented. We have utilized computational molecular modeling to generate a state-ofthe-art large scale structural representation of a bituminous coal of low volatile bituminous rank. This structure(s) has been used to investigate the molecular forces between the bituminous coal structure (or idealized pores) and the molecular species $\mathrm{CH}_{4}$ and $\mathrm{CO}_{2}$. We are close to carrying out molecular dynamics simulations, which will allow us to explore and test the newly created model of coal.
\end{abstract}




\section{TABLE OF CONTENTS}

Page No.

Abstract ............................................................................ 3

List of Graphical Materials ................................................ 5

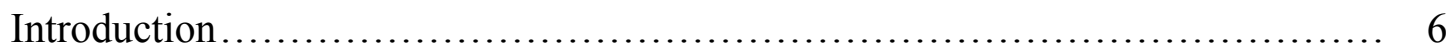

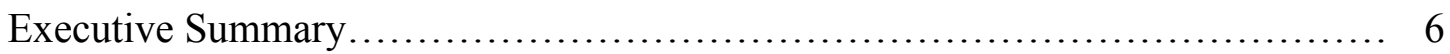

Experimental ................................................................. 7

Results and Discussion ...................................................... 7

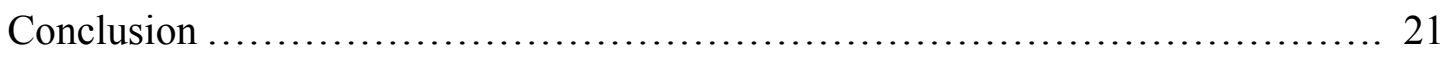

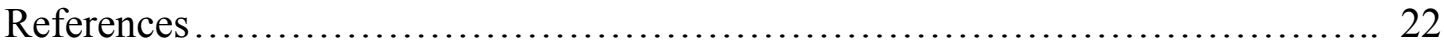

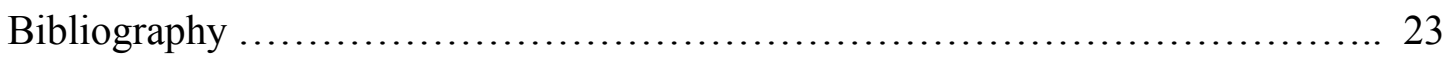

List of Acronyms and Abbreviations ........................................ 24 


\section{LIST OF GRAPHICAL MATERIAL}

Figures 1. The $\mathrm{T}$-structure and the $\mathrm{H}$-structure respectively. These energetic

Page No. minima structures were similar to those found by Sadlej et. al. The interaction energies were found to be $-3.0 \mathrm{kcal} / \mathrm{mol}$ at a distance of $2.80 \AA$ for the Tstructure and $-2.1 \mathrm{kcal} / \mathrm{mol}$ at a distance of $2.20 \AA$ for the $\mathrm{H}$-structure.

Figure 2. Adsorption Isotherm for Methane and Carbon Dioxide on Pocahontas No. 3 coal. Adsorption data is taken from the literature.

Figure 3. Representation showing how much methane (shown at STP) can be obtained (on average) from $10 \mathrm{~g}$ of Pocahontas No. 3 coal.

Figure 4. Representation showing the relationship between micropores (small red spheres), mesopores (yellow sphere-head) and macropore (white

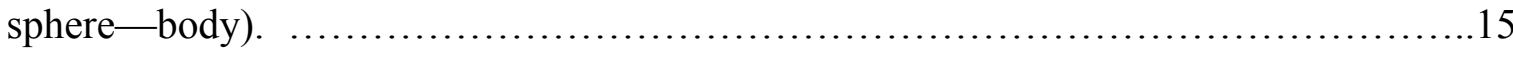

Figure 5. Representation of a micropore and a molecule of $\mathrm{CO}_{2} \quad \ldots \ldots \ldots \ldots \ldots \ldots \ldots \ldots$

Figure 6. Dispersed model structural representation of Pocahontas coal showing a stack of 32 methane molecules that such a structure should contain (average value) and the 64 carbon dioxide molecules that should be able to displace the methane molecules.

Figure 7. Representation of the Pocahontas No. 3 Coal 17

Figure 8. Pore size distribution of the Pocahontas No. 3 coal molecular model ...........18

Figure 9. Representation of the pore volume accessible to specific minimum pore dimension(s)

Figure 10. Representation of the Pocahontas No. 3 coal molecular model with appropriate carbon dioxide content (shown as spheres). Image is generated with a fixed loading simulation with a 2:1 molar ratio of carbon dioxide to methane.

Figure 11. Representation of the Pocahontas No. 3 coal molecular model with appropriate methane content (shown as spheres). Image is generated with a fixed loading simulation.

Figure 12. Representation of the Pocahontas No. 3 coal molecular model with as-received water content shown as ball configuration. 


\section{INTRODUCTION}

Sequestration of $\mathrm{CO}_{2}$ within coal seams that are too deep, thin, or uneconomic has been suggested to slow the rate of climate change. Bituminous coal can hold twice as much $\mathrm{CO}_{2}$, (from sorption isotherm studies) as it can hold methane at $10 \mathrm{MPa}$ gas pressure [1]. Sequestered $\mathrm{CO}_{2}$ displaces $\mathrm{CH}_{4}$ within coal, a valuable fossil fuel, to help offset the sequestration cost. The objective is to carry out first time molecular dynamics simulations to provide useful information on accessible pore volumes, energy of interactions between host and guest molecules, self-diffusion coefficients, identification of likely sorption sites, impact of carbon dioxide sorption/methane exchange upon the coal matrix (expansion/contraction), and competitive adsorption isotherms. The molecular modeling approach essentially permits us to investigate the complex interactions at the molecular level to define and explain the issues relating to sequestration of $\mathrm{CO}_{2}$ within coal. The structural model is being revised to better represent the structural alignment in a coal of this rank which has implications for the shape of pores, interconnection, diffusion, storage capacity, and swelling anisotropy. The objective is to construct a reasonable molecular representation of Pocahontas No. 3 coal which is representative of both the physical and chemical composition, and behavior of this low volatile bituminous coal.

\section{EXECUTIVE SUMMARY}

Recent experimental and computational advances have the potential to produce a first-time reasonable constitutional model (chemical and physical structure) and enable its use. We have utilized computational molecular modeling to generate a state-of-the-art large scale structural representation of a bituminous coal of lower bituminous rank. First, structural diversity was incorporated through the combination of image analysis of highresolution transmission electron microscopy (HRTEM), laser desorption mass spectroscopy, and known coal chemistry which has not been previously included into a three-dimensional structural model of coal. Secondly, methodological advances in molecular simulations that have been successfully applied to biomolecular systems and new engineering materials coupled with available high capacity and high speed parallel super computers make the molecular modeling of $\mathrm{CO}_{2}$ sequestration within coal a realistic and practical reaseach. A major focus of the presented research is in the modification and creation of appropriate force field parameters to model accurately the structure and properties of coal with small molecules such as $\mathrm{CO}_{2}$ and $\mathrm{CH}_{4}$. Molecular models of $\mathrm{CO}_{2}$ have been evaluated with water to analyze which classical molecular force-field parameters are the most reasonable to predict $\mathrm{CO}_{2}$ interactions with water. (Why water? A starting point?) The molecular force field models for a single $\mathrm{CO}_{2}-\mathrm{H}_{2} \mathrm{O}$ complex were compared against quantum mechanical calculations, to develop a reasonable aqueous force field model for $\mathrm{CO}_{2}$. All of the structural calculations show that two structures exist for the interaction of a $\mathrm{CO}_{2}$ with a water molecule, called the $\mathrm{H}$ structure and T-structure. It was found that the Steele model was the best literature model with respect to reproducing both structures from the $a b$ initio data; the newly developed TJDM1 $\mathrm{CO}_{2}$ model reproduced the interaction energies and geometries significantly better than the Steele force field model. The newly development three-dimensional 
structure(s) has been used to investigate the molecular forces between the bituminous coal structure (or idealized pores) and the molecular species $\mathrm{CH}_{4}$ and $\mathrm{CO}_{2}$ using the newly developed force field. We have made progress in carrying out large scale molecular dynamics simulations using the CHARMM force field in order to refine our coal model. There have been two issues facing us over the last year. First, we have had to create a completely new topology and parameter definition for coal. Since we are using a classical force field, we have adopted the strategy of treating coal composed of individual common fragments based upon mass, composition and bonding. Over 50 fragments have been identified in our first approximation of a generalizable force field for coal. Our procedure is similar to treating a protein as being composed of the discrete set of amino acids. Our approach will allow other researchers to study coal structure behavior and properties with large-scale structural model for the first time. Second, we have had to incorporate the quality $\mathrm{CO}_{2}$ parameters that we have developed over the last two years. There are the geometric and arithmetic procedures, which we have successfully implemented. We are creating a new and generalizable force field for coal simulations.

\section{EXPERIMENTAL}

Over the last year, we have added two new super computers to help complete this project. In terms of super computing facilities, we have used a SGI Altix 3700 system (32 processors@1.5 GHz with 64 GB of memory and 1.6 TB of disk); SGI Altix 350 (16 processors@1.5 GHz with $16 \mathrm{~GB}$ of memory and $1.6 \mathrm{~TB}$ of disk); IBM RISC System/6000 SP Supercomputer Model 3A8 (four nodes@160 MHz each w/256 Mb ECC memory, twelve nodes@120 MHz each w/1 GB ECC memory); 2 IBM RISC System/6000 (77 MHz and $66 \mathrm{MHz}$ w/512 Mb ECC memory); and $2 \mathrm{Dec}$ Alpha Beowulf Clusters containing Master-node $(600 \mathrm{MHz}$ w/512 MB ECC memory and 24 GB of disk space) and 16 nodes (600 MHz w/256 MB ECC memory) were utilized. Twenty 1.8-3.2 $\mathrm{GHz}$ Pentium IV computers with molecular computation and data processing software were utilized to visualize and setup larger computations.

\section{RESULTS AND DISCUSSION}

\section{Data Reduction}

We have made progress in carrying out large scale molecular dynamics simulations using the CHARMM force field in order to refine our coal model. First, we have had to create a completely new topology and parameter definition for coal. This means that each of the force field parameters much be explicitly defined and parameterized. This specific approach has several draw backs. First, the created force field will be of use on only the system for which it was designed. Second, the number of force field elements and parameters will be applied to systems of over $250 \mathrm{~K}$ particles. As such, it will be difficult to create and manage such a database with any degree of accuracy. Therefore, we have adopted the strategy of treating coal composed of individual common fragments based upon mass, composition and bonding. Our

procedure is similar to treating a protein as being composed of the discrete set of amino acids. Second, we have had to incorporate the quality $\mathrm{CO}_{2}$ parameters that we have 
developed over the last two years. There are the geometric and arithmetic procedures, which we have successfully implemented.

We are building upon our previous results from quantum chemical computations. The $\mathrm{CO}_{2}$ parameters were derived from $a b$ initio calculations for a $\mathrm{CO}_{2}$ molecule, a single water molecule, and the $\mathrm{CO}_{2}-\mathrm{H}_{2} \mathrm{O}$ complex at multiple levels of theory and basis sets in order to calculate the interaction energy of the complex. For the interaction energies, they were calculated as the energy of the complex minus the energies of the individual $\mathrm{CO}_{2}$ and water molecules.[1]. This can be shown below:

$$
\Delta E=E(A B)-E(A)-E(B)
$$

where delta $\mathrm{E}$ is the energy of interaction, $\mathrm{E}(\mathrm{AB})$ is the energy of the complex, and $\mathrm{E}(\mathrm{A})$ and $\mathrm{E}(\mathrm{B})$ are the energies of the $\mathrm{CO}_{2}$ and water molecules[1].

A thorough evaluation of the $\mathrm{CO}_{2}-\mathrm{H}_{2} \mathrm{O}$ complex was achieved by using different theory and basis sets. Hartree-Fock (HF), density functional theory (DFT), MöllerPlesset perturbation theory (MPPT), and coupled clusters with single and double excitations (CCSD) were used with the following basis sets: 3-21G, 6-31G, 6-31G(d), aug-cc-pvdz, and aug-cc-pvtz. The density functional theory used in the calculations was the Becke3 exchange functional with the Lee, Yang, and Parr non-local functional corrections [2, 3]. For the most complete QM study of the complex, the use of polarized split-valence basis sets were employed to allow the molecular orbitals to change shape by adding basis functions to higher than ground state levels to increase angular momentum and efforts were made to keep a balanced basis set in the calculations [1,4]. The investigation with the increasing levels of theory was in an attempt to converge the interaction energies and the $a b$ initio calculations were done using Gaussian98 and Gaussian03 [5, 6].

The zero point energy calculations were obtained by releasing the constraints of the system until all degrees of freedom were free. The minima were obtained and frequency calculations were completed and evaluated with all of the above mentioned methods and basis sets. The energetic minima were found to have no negative frequencies, concluding that the true minimum was found for both the T-structure and the $\mathrm{H}$-structure of the complex. The T-structure was also constrained to $\mathrm{C}_{2 \mathrm{~V}}$ symmetry, as had been done in previous $a b$ initio calculations and frequency calculations on the minimized structure for comparison [7].

For the classical simulations, including both the $\mathrm{MM}$ minimizations and $\mathrm{MC}$ simulations, a classical force field was used to model the $\mathrm{CO}_{2}-\mathrm{H}_{2} \mathrm{O}$ interactions; the waters in the bulk phase simulations were modeled in the same fashion. The potential energy function of the force field is given as follows [8].

$U(R)=U(R)_{\text {bonded }}+U(R)_{\text {non-bonded }}$

where

$U(R)_{\text {bonded }}=\sum_{\text {bonds }} K_{b}\left(b-b_{0}\right)^{2}+\sum_{\text {angles }} K_{\theta}\left(\theta-\theta_{0}\right)^{2}+\sum_{\text {dihedrals }} K_{\chi}[1+\cos (n \chi-\sigma)]$ 
and

$$
U(R)_{\text {non-bonded }}=\sum_{\substack{\text { non-bonded } \\ \text { pairs }}}\left(\varepsilon_{i j}\left[\left(\frac{R_{\min . i j}}{r_{i j}}\right)^{12}-\left(\frac{R_{\min . i j}}{r_{i j}}\right)^{6}\right]+\frac{q_{i} q_{j}}{\varepsilon_{D} r_{i j}}\right)
$$

where $\mathrm{U}(\mathrm{R})$ is the potential energy of the system. For the $\mathrm{CO}_{2}-\mathrm{H}_{2} \mathrm{O}$ complexes, the only parameters that will be evaluated will be the non-bonded terms, since the $\mathrm{CO}_{2}$ and water will be treated as rigid molecules. The standard mixing rules for the mixing of the LJ terms between molecules was observed [4]. The mixing rules can be shown as:

$$
\sigma_{A B}=\frac{\sigma_{A A}+\sigma_{B B}}{2} \quad \text { (5) and } \quad \varepsilon_{A B}=\sqrt{\varepsilon_{A A} \varepsilon_{B B}}
$$

The DYNAMO program was used to perform the MM minimizations and BOSS was used in the MC simulations $[9,10]$. The MM minimizations were done using several steps of steepest decent followed by conjugate gradient, in order to find the lowest energy structures; the complexes interaction energies were calculated using the same methods in the $a b$ initio calculations shown in Equation 1. The MC simulations were standard done using the standard acceptance/rejection ratio of $0.40 / 0.60$, which has been shown to give reasonable sampling in simulations [4].

The force-field parameters used in the molecular mechanics calculations were taken from the literature and developed here. The water molecules used in the simulations the TIP3P and TIP4P water models from Jorgensen et. al. [11, 12]. Several $\mathrm{CO}_{2}$ models from the literature were studied along with a newly developed model, the TJDM1 model (named from the authors initials) [13-15]. All the $\mathrm{CO}_{2}$ models used in the calculations are 3-site electrostatic models with the charges and LJ 12-6 terms centered on the atoms. The intermolecular terms for the various $\mathrm{CO}_{2}$ models are presented in Table 1.

\section{Experimental and Operational Data}

We have incorporated the quality parameters $\mathrm{CO}_{2}$ parameters into the CHARMM force field in order to refine our coal model by running molecular dynamics simulations. However, to simulate coal in the CHARMM program, we can either define every possible element of the force field or identify patterns that can be used to substantially increase the speed, accuracy and understanding of the simulations. As such, a full definition of the parameters for the force field would be exceedingly large, cumbersome, redundant, difficult to manage, and provide opportunities for sources of error. Therefore, we have elected to identify patterns, since in our large scale simulations the number of atoms exceeds over 250 thousand.

To incorporate the parameters into the CHARMM program, our strategy is to identify and create "fragments" of reoccurring patterns of coal pieces. There are a much larger number of coal fragments than in 20 amino acids of proteins; however, we are determined to explore this point, since it will allow use to systematically develop high quality models of coal consistent with experimental data. So far we have identified 
approximately 8 specific repeating fragments within coal that we treat as monomers. We suspect that the number of fragments will exceed 50 specific patterns. We have decided to use this limited set as a trial point, so that we can work out the methodology of treating coal as a polymer. In CHARMM language, we have had to create a completely new topology and parameter definition for coal. We are midstream in this process and should have developed the necessary software by this fall.

The fragments identified are based upon molecular mass, elements and bonding scheme. The fragments will be fully described in the next report.

Molecular models of $\mathrm{CO}_{2}$ have been evaluated with water to analyze which classical molecular force-field parameters are the most reasonable to predict $\mathrm{CO}_{2}$ interactions with water. The molecular force field models for a single $\mathrm{CO}_{2}-\mathrm{H}_{2} \mathrm{O}$ complex were compared against quantum mechanical calculations, to develop a reasonable aqueous force field model for $\mathrm{CO}_{2}$. All of the structural calculations show that two structures exist for the interaction of a $\mathrm{CO}_{2}$ with a water, called the H-structure and $\mathrm{T}$ structure. It was found that the Steele model was the best literature model with respect to reproducing both structures from the $a b$ initio data; the newly developed TJDM1 $\mathrm{CO}_{2}$ model reproduced the interaction energies and geometries significantly better than the Steele force field model.

Table1: The $\mathrm{CO}_{2}$ force field parameters from the literature and the developed TJDM1 model [13-15].

\begin{tabular}{c|c|ccc} 
Carbon dioxide model & & $\boldsymbol{\varepsilon}$ & $\boldsymbol{\sigma}$ & $\mathbf{q}$ \\
\hline Harris (EPM) & $\mathbf{C}$ & 0.057627 & 2.785 & 0.6645 \\
& $\mathbf{O}$ & 0.164933 & 3.064 & -0.33225 \\
\hline Murthy & $\mathbf{C}$ & 0.057629 & 2.785 & 0.596 \\
& $\mathbf{O}$ & 0.165138 & 3.014 & -0.298 \\
\hline Steele & $\mathbf{C}$ & 0.057629 & 2.652 & 0.596 \\
& $\mathbf{O}$ & 0.165138 & 2.870 & -0.298 \\
\hline Harris2 (EPM2) & $\mathbf{C}$ & 0.055898 & 2.757 & 0.6512 \\
& $\mathbf{O}$ & 0.159985 & 3.033 & -0.3256 \\
\hline TJDM1 & $\mathbf{C}$ & 0.087630 & 2.152 & 0.720 \\
& $\mathbf{O}$ & 0.13714 & 3.080 & -0.360 \\
\hline
\end{tabular}

Using $a b$ initio quantum chemical calculations, two energy minima were located for the $\mathrm{CO}_{2}-\mathrm{H}_{2} \mathrm{O}$ complex. The two energetic minima for the $\mathrm{CO}_{2}-\mathrm{H}_{2} \mathrm{O}$ complex are in agreement with previous work done by Sadlej et. al., with one noted exception, where these minima were called the H-structure and the T-structure based on the geometry of the atoms in the complex[7]. Shown in Figures 1 and 2 are the T-structure and the Hstructure, respectively.

The noted exception from the previous work done by Sadlej et. al. held the Tstructure to a constrained to $\mathrm{C}_{2 \mathrm{~V}}$ symmetry based on assumptions from experimental microwave data [16]. This current study did frequency calculations on constrained Tstructures minimized at several levels of theory and basis sets and found that negative 
frequencies existed in every case of the constrained structure. The first principle quantum mechanical calculations shown in this study were done with no symmetry constraints on the complex. Calculation of the frequencies with all degrees of freedom released showed that true energy minima were obtained.

The T-structure is the global minimum for the $\mathrm{CO}_{2}-\mathrm{H}_{2} \mathrm{O}$ complex in all the levels of theory and basis sets. It exhibits 2 electrostatic interactions between the carbon dioxide and the water, one between the oxygen of the water with the carbon of the $\mathrm{CO}_{2}$ and the second between a hydrogen of the water and an oxygen of the $\mathrm{CO}_{2}$. Shown in Tables 2 and 3 are the interaction energies and geometric distances between the $\mathrm{CO}_{2}$ and water for the T-structure. This is in disagreement with the reported T-structure from Sadlej, where he held the $\mathrm{CO}_{2}-\mathrm{H}_{2} \mathrm{O}$ T-structure complex in $\mathrm{C}_{2 \mathrm{~V}}$ symmetry, which would prevent the second electrostatic interaction between the molecules from forming.
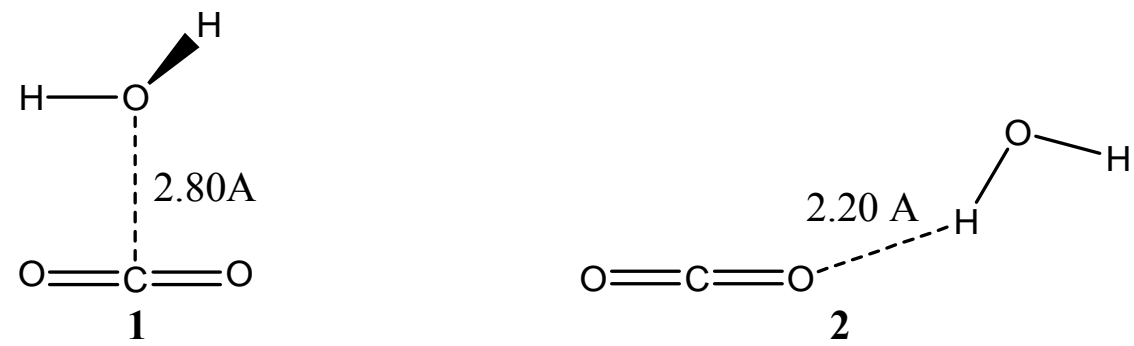

Figure 1: The T-structure (1) and the H-structure (2) are shown. These energetic minima structures were similar to those found by Sadlej et. al. The interaction energies were found to be $-3.0 \mathrm{kcal} / \mathrm{mol}$ at a distance of $2.80 \AA$ for the T-structure and $-2.1 \mathrm{kcal} / \mathrm{mol}$ at a distance of $2.20 \AA$ for the $\mathrm{H}$-structure.

Table 2: Interaction energies of the T-structure; energies given in $\mathrm{kcal} / \mathrm{mol}$.

\begin{tabular}{ccccccc}
\hline b.s. / method & B3LYP & HF & MP2 & MP3 & MP4 & CCSD \\
\hline 3-21G & -8.30 & -7.97 & -6.64 & -7.45 & -6.91 & -7.16 \\
$6-31 G$ & -5.18 & -5.81 & -4.46 & -5.48 & -4.96 & -5.45 \\
$6-31 G(d)$ & -3.41 & -3.10 & -3.69 & -3.82 & -3.68 & -3.72 \\
aug-cc-pvdz & -1.95 & -2.67 & -2.99 & -2.95 & -3.00 & \\
aug-cc-pvtz & -1.79 & -2.56 & -2.81 & & & \\
\hline
\end{tabular}

Table 3: Geometry of T-Structure: The distance between the $\mathrm{C}\left(\mathrm{CO}_{2}\right)$ and the $\mathrm{O}\left(\mathrm{H}_{2} \mathrm{O}\right)$, in $\AA$.

\begin{tabular}{ccccccc}
\hline b.s. / method & B3LYP & HF & MP2 & MP3 & MP4 & CCSD \\
\hline 3-21G & 2.514 & 2.592 & 2.616 & 2.525 & 2.583 & 2.562 \\
$6-31 G$ & 2.576 & 2.586 & 2.696 & 2.619 & 2.659 & 2.647 \\
6-31G(d) & 2.772 & 2.774 & 2.749 & 2.723 & 2.721 & 2.730 \\
aug-cc-pvdz & 2.847 & 2.841 & 2.783 & 2.816 & 2.785 & \\
aug-cc-pvtz & 2.869 & 2.858 & 2.777 & & & \\
\hline
\end{tabular}


From the T-structure $a b$ initio data it is observable that the energies of interaction and the distances between the molecules converge going across and down the tables, converging in both the levels of theory and in number of basis sets respectively. The convergence of the methods and basis sets reached a limiting value of $-3.0 \mathrm{kcal} / \mathrm{mol}$ for the interaction energy and $2.80 \AA$ for the distance between the molecules. These are the values that will be used in the comparison with the molecular mechanics values.

The second minima found was for the H-structure, which was similar to that found by Sadlej. The H-structure exhibits hydrogen bonding between a hydrogen of the water molecule and an oxygen of the $\mathrm{CO}_{2}$ molecule. Shown in Tables 4 and 5 are the interaction energies and geometric distances between the $\mathrm{CO}_{2}$ and the water molecule. As seen in the T-structure $a b$ initio data, the H-structure $a b$ initio data also converge going across and down the tables, converging in both the levels of theory and in number of basis sets respectively. The convergence of these values reaches a limiting value of -2.1 $\mathrm{kcal} / \mathrm{mol}$ for the interaction energy and $2.20 \AA$ for the distance between the molecules. As before, these are the values that will be used in the comparison with the molecular mechanics values.

Table 4: Interaction energies of the H-structure; energies given in $\mathrm{kcal} / \mathrm{mol}$.

\begin{tabular}{ccccccc}
\hline b.s. / method & B3LYP & HF & MP2 & MP3 & MP4 & CCSD \\
\hline 3-21G & -4.38 & -4.16 & -4.34 & -4.29 & -4.34 & -4.32 \\
6-31G & -3.03 & -2.91 & -2.74 & -2.92 & -2.89 & -3.19 \\
6-31G(d) & -2.07 & -1.77 & -2.25 & 2.21 & -2.21 & -2.19 \\
aug-cc-pvdz & -1.36 & -1.33 & -2.11 & -2.10 & -2.08 & \\
aug-cc-pvtz & -1.35 & -1.24 & -2.05 & & & \\
\hline
\end{tabular}

The development of the force field parameters was achieved by minimizing the error of both the $\mathrm{MM}$ calculated $\mathrm{H}$-structure and the $\mathrm{T}$-structure against the QM convergence structures. To start the development, the $\varepsilon, \sigma$, and $\mathrm{q}$ were all adjusted $\pm 15 \%$ of the original values, which were started from the Steele structure, and the difference in the energetics and structure were noted. From this, it was found that the charge was the contributing the most in the energetics and structure deviation, followed by $\sigma$, and then the well depth, $\varepsilon$. To minimize the change in the original parameters, the charge was optimized followed, by the $\sigma$, and then $\varepsilon$. Several other trials were attempted using other error minimization processes, but it was found that the previously mentioned one was the closest to the original parameters. These parameters were used in the initial solubility calculations, but were modified to the parameters noted in Table 1 to achieve the correct solubility; the difference between the original development described here and the final was found to be $<1 \%$, and thus the original parameters are omitted, but noted to give slightly better structural properties by $<2 \%$. 
Table 5: Geometry of H-Structure: The distance between the $\mathrm{O}\left(\mathrm{CO}_{2}\right)$ and the $\mathrm{H}\left(\mathrm{H}_{2} \mathrm{O}\right)$, in $\AA$.

\begin{tabular}{ccccccc}
\hline b.s. / method & B3LYP & HF & MP2 & MP3 & MP4 & CCSD \\
\hline 3-21G & 1.997 & 2.061 & 2.055 & 2.059 & 2.056 & 2.060 \\
6-31G & 2.082 & 2.136 & 2.161 & 2.147 & 2.161 & 2.160 \\
6-31G(d) & 2.195 & 2.301 & 2.216 & 2.228 & 2.233 & 2.261 \\
aug-cc-pvdz & 2.234 & 2.355 & 2.182 & 2.196 & 2.203 & \\
aug-cc-pvtz & 2.266 & 2.382 & 2.187 & & & \\
\hline
\end{tabular}

The MM minimizations were performed using a variety of minimization steps, in order to insure the finding of the lowest energy structure with some degree of accuracy. It was found that no improvement was gained by going over 100 steps of steepest decent, followed by 200 steps of conjugate gradient minimization steps in the minimization process, when starting from a reasonable starting structure. It is also noted that the tolerance for the minimization method were kept low, in order that the barrier from the Tstructure to the H-structure was not cross in the process.

Table 6: The interaction energies of the four literature $\mathrm{CO}_{2}$ models and the developed TJDM1 model with TIP4P water model and comparison to the $a b$ initio calculations; interaction energies given in $\mathrm{kcal} / \mathrm{mol}$.

\begin{tabular}{|c|c|c|c|c|}
\hline & \multicolumn{2}{|c|}{ T-Structure } & \multicolumn{2}{c|}{ H-Structure } \\
\hline & $\mathrm{MM}$ & $\Delta(\mathrm{QM}-\mathrm{MM})$ & $\mathrm{MM}$ & $\Delta(\mathrm{QM}-\mathrm{MM})$ \\
\hline Harris & -2.26 & -0.74 & -1.93 & -0.17 \\
\hline Murthy & -2.08 & -0.92 & -1.73 & -0.37 \\
\hline Steele & -2.27 & -0.73 & -1.98 & -0.12 \\
\hline Harris2 & -2.26 & -0.74 & -1.94 & -0.16 \\
\hline TJDM1 & -2.65 & -0.35 & -2.08 & -0.02 \\
\hline
\end{tabular}

Table 7: The geometric distances of the four literature $\mathrm{CO}_{2}$ models and the developed TJDM1 model with TIP4P water model and comparison to the $a b$ initio calculations; distances given in $\AA$.

\begin{tabular}{|c|l|c|c|c|}
\hline & \multicolumn{2}{|c|}{ T-Structure } & \multicolumn{2}{c|}{ H-Structure } \\
\hline & MM & $\Delta(\mathrm{QM}-\mathrm{MM})$ & $\mathrm{MM}$ & $\Delta(\mathrm{QM}-\mathrm{MM})$ \\
\hline Harris & 2.934 & -0.134 & 2.010 & -0.190 \\
\hline Murthy & 2.935 & -0.135 & 2.038 & -0.162 \\
\hline Steele & 2.838 & -0.038 & 1.880 & -0.320 \\
\hline Harris2 & 2.914 & -0.114 & 1.993 & -0.207 \\
\hline TJDM1 & 2.808 & +0.008 & 2.008 & -0.192 \\
\hline
\end{tabular}


Among the molecular force field models found in the literature, the Steele model provides the best match with the $a b$ initio data, with an interaction energy and distance of $-2.27 \mathrm{kcal} / \mathrm{mol}$ and $2.84 \AA$ respectively for the T-structure and $-1.98 \mathrm{kcal} / \mathrm{mol}$ and $1.88 \AA$ respectively for the $\mathrm{H}$-structure. This yielded a difference, when compared to the $a b$ initio, of $-0.73 \mathrm{kcal} / \mathrm{mol}$ and $-0.04 \AA$ for the T-structure and $-0.12 \mathrm{kcal} / \mathrm{mol}$ and $-0.32 \AA$ for the $\mathrm{H}$-structure. The deviations of the literature $\mathrm{CO}_{2}$ models from the $a b$ initio data are noted to be not within reason agreement and therefore would not be accurate in aqueous simulations. The developed TJDM1 force field model yields dramatic improvements over the Steele model, when compared to the $a b$ initio data. The interaction energies and distances of the T-structure were found to be $-2.65 \mathrm{kcal} / \mathrm{mol}$ and $2.81 \AA$ respectively and the $\mathrm{H}$-structure yielded results of $-2.08 \mathrm{kcal} / \mathrm{mol}$ and $2.01 \AA$ respectively. The differences between the TJDM1 model and the $a b$ initio are -0.35 $\mathrm{kcal} / \mathrm{mol}$ and $0.01 \AA$ for the T-structure and $-0.02 \mathrm{kcal} / \mathrm{mol}$ and $-0.19 \AA$ for the $\mathrm{H}$ structure. This shows much improvement over the Steele and all of the other compared models. A comparison of the molecular force field model's interaction energies and interaction distances can be seen in Tables 6 and 7 .

A representation if an adsorption isotherm for Pocahontas No. 3 is shown in Figure 2. Clearly the 2:1 ratio is pressure dependent. The Pocahontas coal is also very rich in methane content as shown in Figure 3.

\section{Adsorption Isotherms for Carbon Dioxide and Methane}

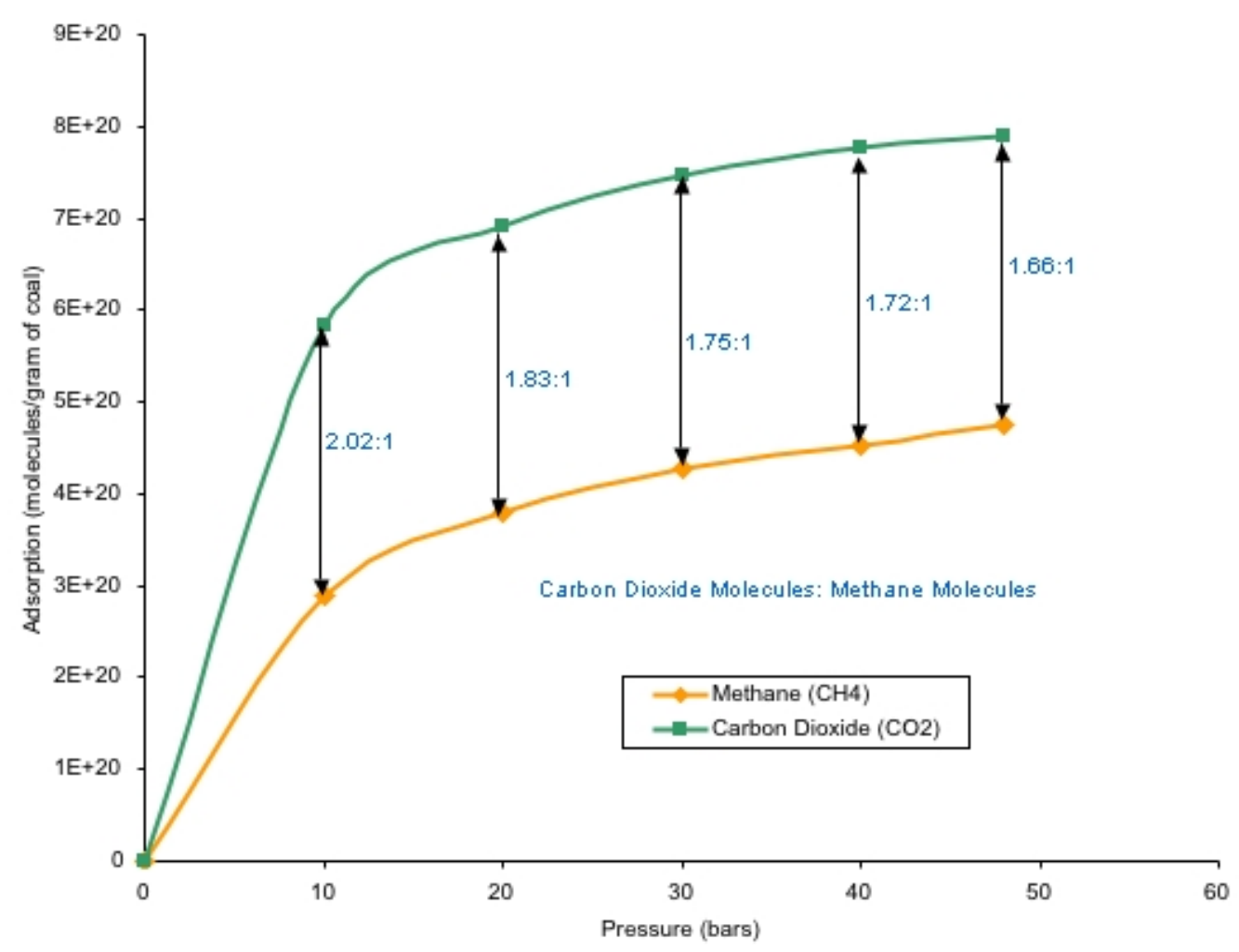

Figure 2. Adsorption Isotherm for Methane and Carbon Dioxide on Pocahontas No. 3 coal. Adsorption data is taken from the literature. 


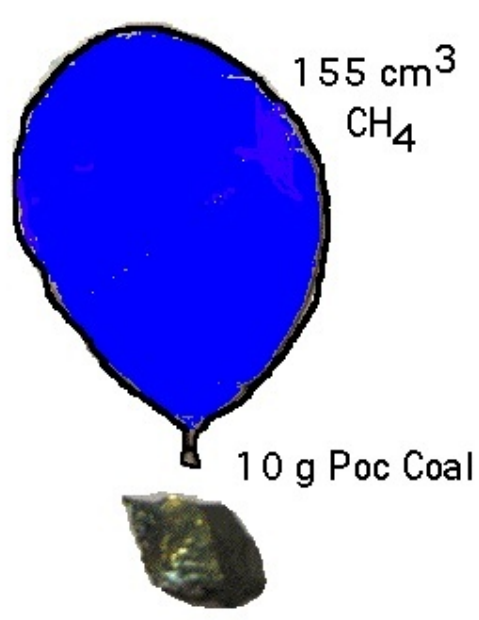

Figure 3. Representation showing how much methane (shown at STP) can be obtained (on average) from $10 \mathrm{~g}$ of Pocahontas No. 3 coal.

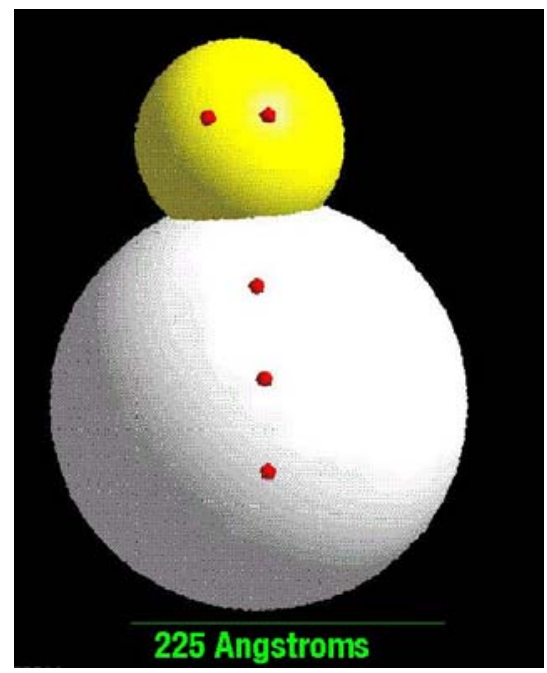

Figure 4. Representation showing the relationship between micropores (small red spheres), mesopores (yellow sphere-head) and macropore (white sphere-body).

The complex interconnection, distribution, and shapes of the pores are the controlling

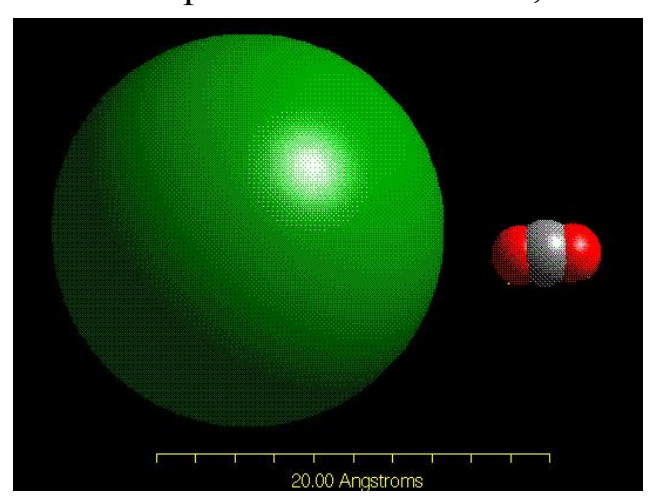

Figure 5. Representation of a $19.99 \AA$ micropore (represented as a sphere and a molecule of $\mathrm{CO}_{2}$ features with regard to capacity and kinetics of uptake. Figure 4 shows the representation of the relative scale of macro, meso, and micropores, (shown as spheres.) The dual porosity nature of the coal means for the most part that mesoporosity is limited for this rank. Shown in Figure 5 is the relative scale of a micropore (shown as sphere) and a $\mathrm{CO}_{2}$ molecule. We believe that the distribution, size and shape of the micropores limits access to the methane molecules while permitting carbon dioxide to enter (molecular sieving). Shown in Figure 6 is a "blow-up" structural model with the fragments dispersed in space to aid in viewing. Also shown are the 32 molecules of methane that a structure of this size should contain (based on average methane content values for this coal) and the 64 carbon dioxide molecules that can displace the methane (assuming 2:1 ratio). 


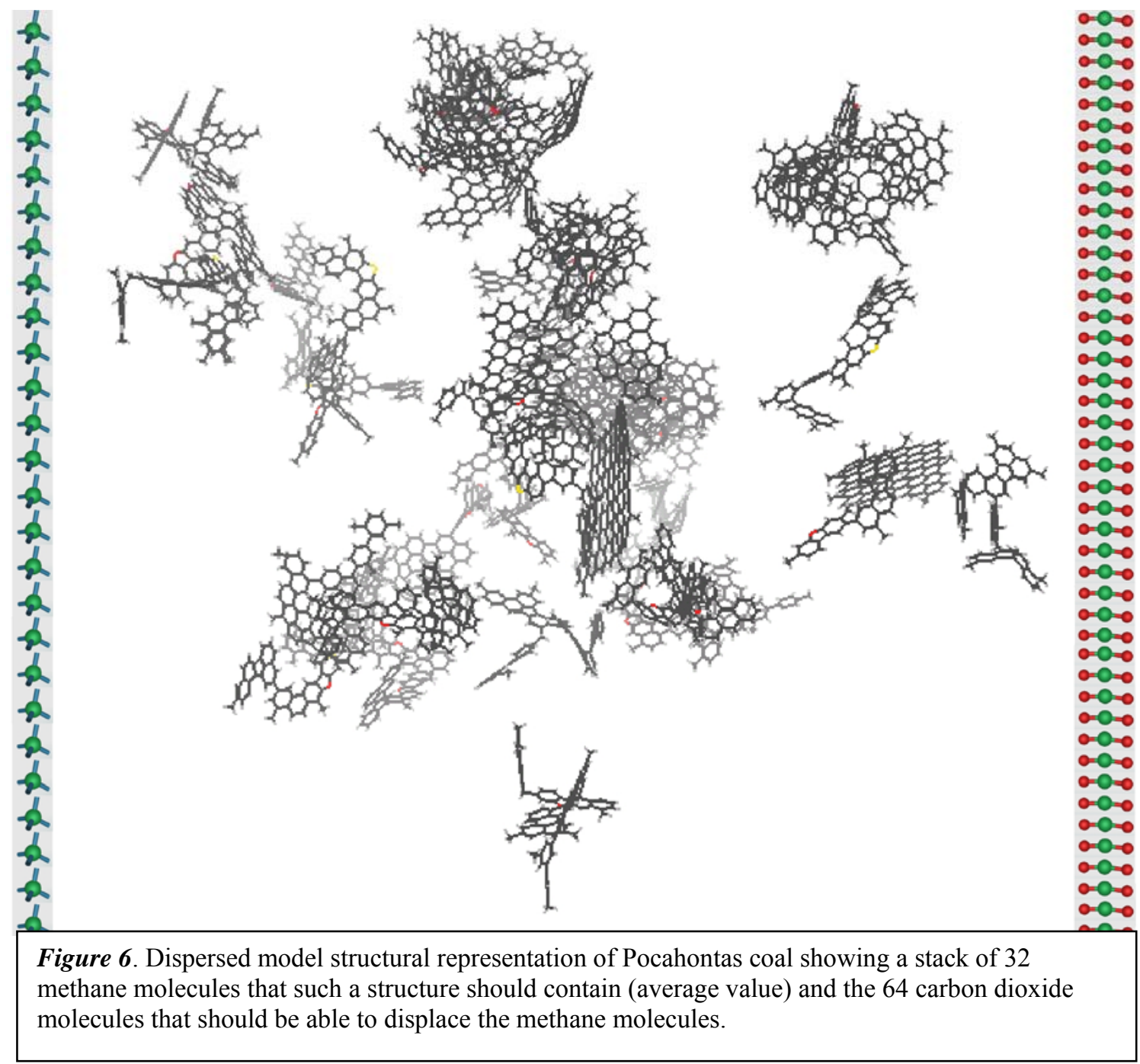

The scale of the molecular representation was increased to better represent the structural diversity present within the coal. The larger-scale representation is shown in Figure 7. This model is the largest coal representation ever generated and represents the state-ofthe-art of coal molecular modeling. The model is large and consists of 20,000 atoms. The simulated helium density is $1.27 \mathrm{~g} / \mathrm{cm}^{3}$, close to the experimentally-derived value of 1.34 $\mathrm{g} / \mathrm{cm}^{3}$. The final formula of this model is $\mathrm{C}_{13471} \mathrm{H}_{8143} \mathrm{O}_{113} \mathrm{~N}_{181} \mathrm{~S}_{23}$ and is contained in a periodic crystal box with parameters of $\mathrm{A}=62.5 \AA \mathrm{B}=55.9 \AA$ and $\mathrm{C}=112.1 \AA$. 


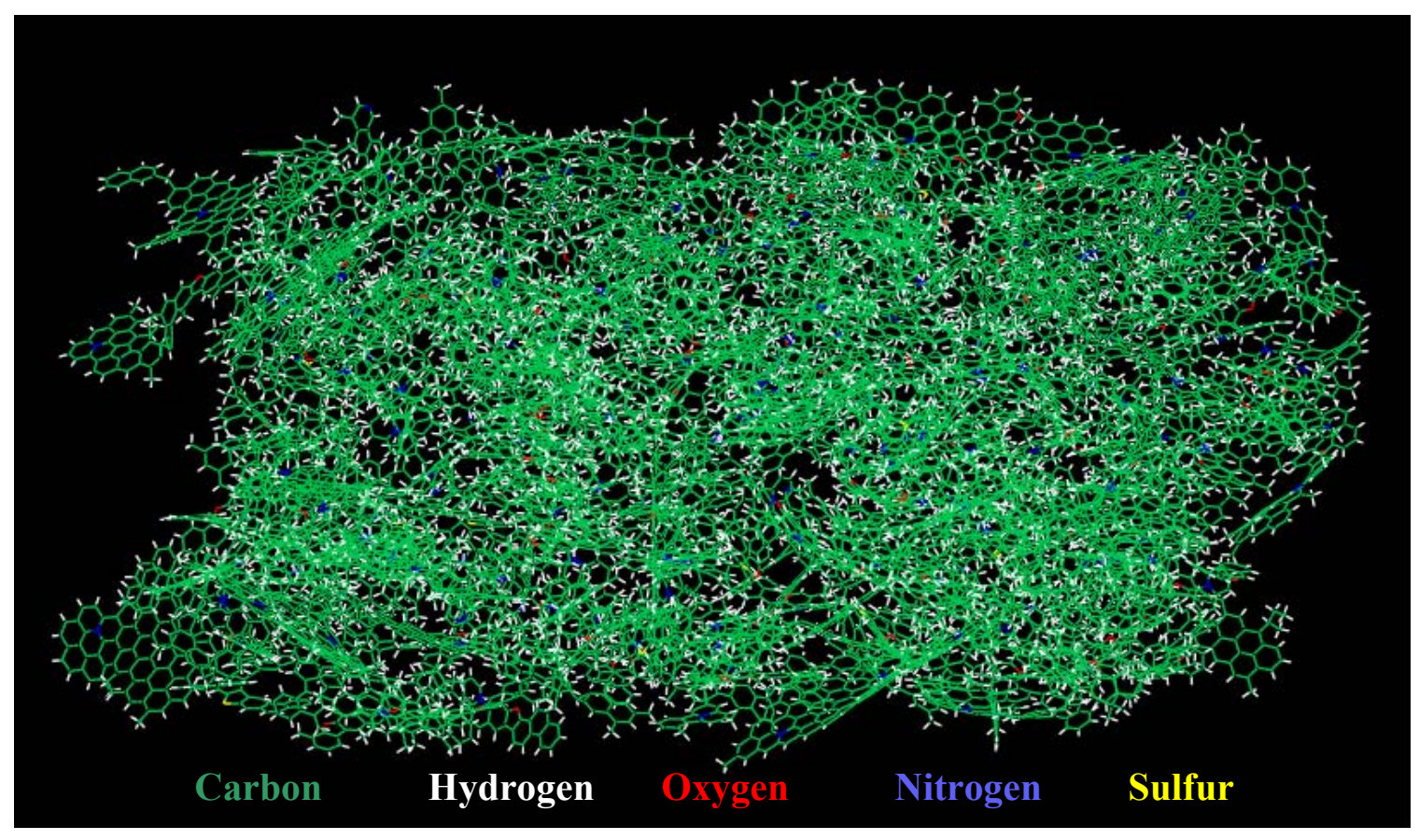

Figure 7. Structural representation of the Pocahontas No. 3 coal molecular model.

The pore size distribution was determined using the POR program, which determines open and closed porosity within the molecular model based on a $1 \AA$ cubic grid elucidation. The distribution obtained is shown in Figure 8. Note that much of the porosity is ultra-microporous and not available to sequester $\mathrm{CO}_{2}$. Given the size of the structure $(60 \AA)$ no mesopores or macropores are contained within the structure,. However, for a coal of this rank the bulk of the porosity is microporous. Utilizing literature values for pore size accessability it is possible to predict the pore volume accessible to sorbate molecules. The predictions are shown in Figure 9. Using 5.08 $\AA$ for helium accessible pores (pores below this size being closed to helium) to define $100 \%$ of the porosity, $\mathrm{CO}_{2}$ can access $\left(5.7 \AA\right.$ pores and above) about $75 \%$ and $\mathrm{CH}_{4}(6.1 \AA)$ about $58 \%$ of the available porosity. With increased sophistication, sorbate motion, molecular relaxation and rearrangement there is likely to be a substantial increase for the model to sorb high quantities of $\mathrm{CO}_{2}$. Higher-level modeling is likely to better elucidate the $2: 1$ ratio expected for this structure at gas pressure representing 10 bar (likely sequestration conditions). 


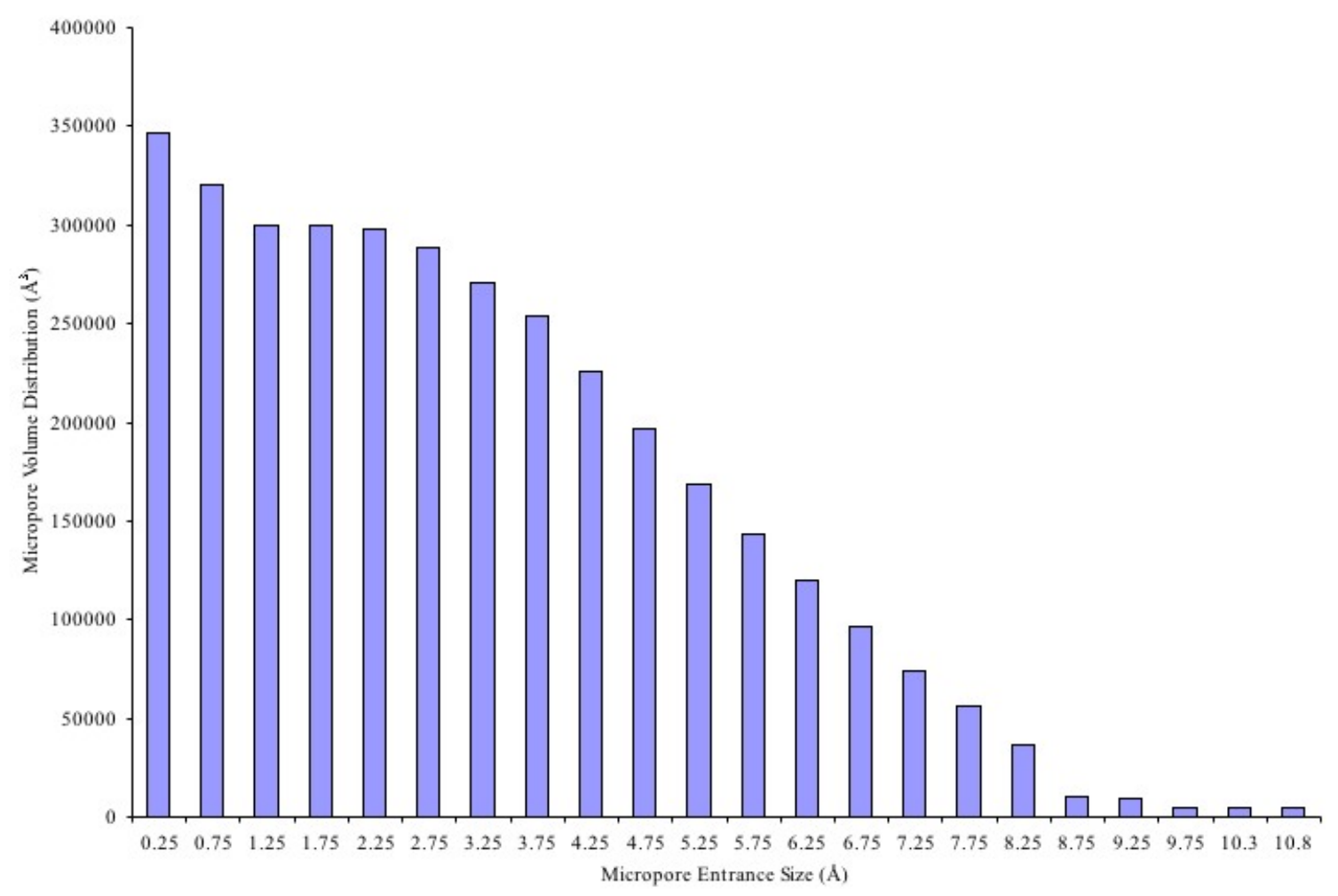

Figure 8. Pore size distribution of the Pocahontas No. 3 coal molecular model.

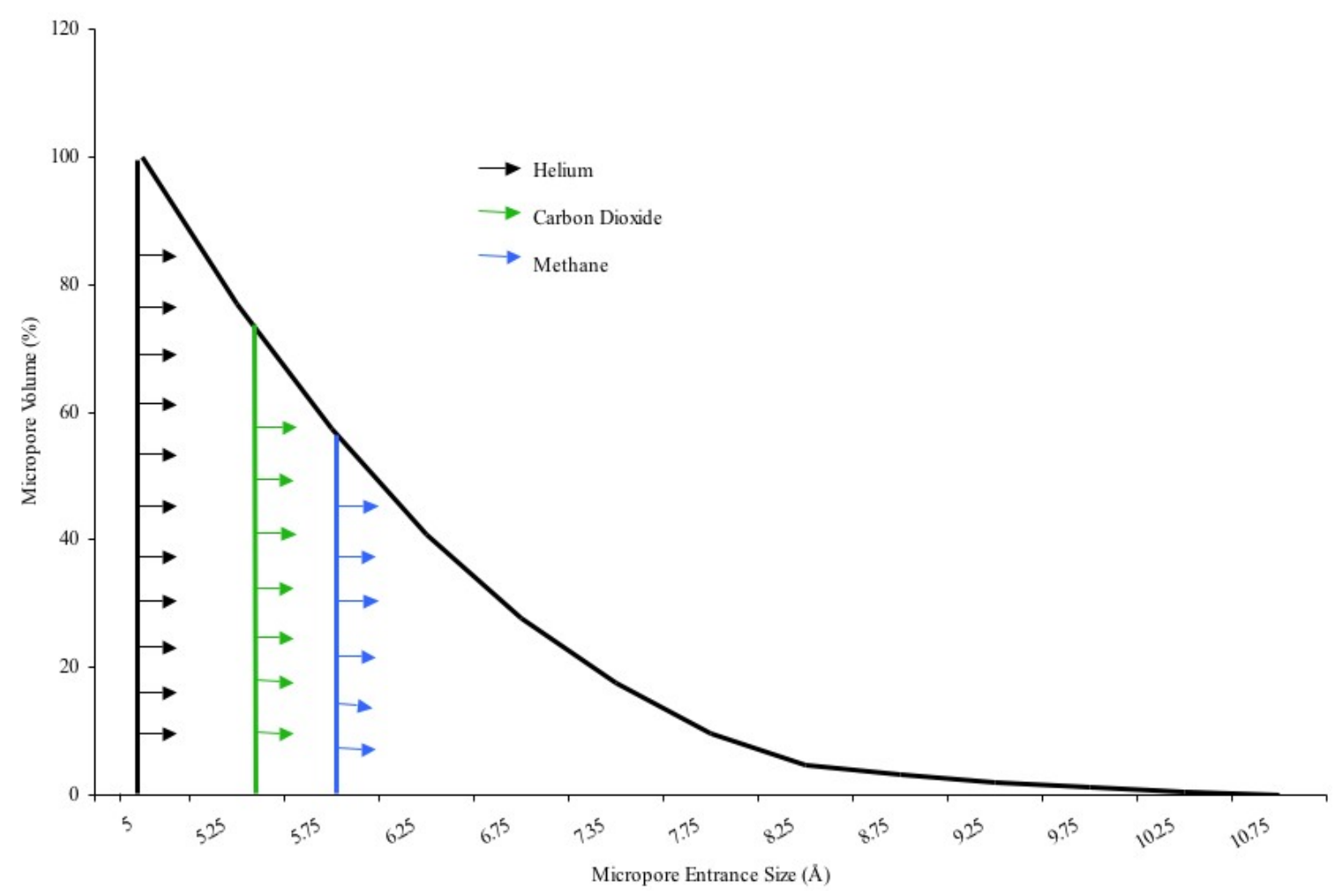

Figure 9. Representation of the pore volume accessible to specific minimum pore dimension(s) 
The sorption module within Cerius2 was used to have a low-level modeling approach prior to going to the computation expense of molecular dynamics. The sorption generates random configurations by translating and rotating, and possibly creating and destroying sorbate molecules in the model framework. After this is completed, Sorption either accepts or rejects the configurations based on the energy (or pressure, as with the fixed pressure method). The energy is calculated based on the interaction between the sorbate molecules to the structure, as well as the sorbate molecules to each other. A sorbate is rejected (or destroyed) from the model if the energy between it and the structure is too high (termed a bad contact). The configuration is rejected if any sorbate and framework atoms are closer to each other than half of their van der Waals radii. The size of a random translation or rotation move for a given sorbate is limited by the maximum step size (with default values being $1 \AA$ for translation and $50^{\circ}$ for the rotation).

The fixed loading method works by placing the sorbate in a random spot in the structure. Each subsequent configuration is generated by either a random translation or random rotation of that sorbate molecule. If the energy change from the random translation or rotation is negative, then the configuration is accepted. If the energy change is positive, then the molecule's Boltzmann factor is calculated and compared to a randomly generated number between zero and one; if the Boltzmann factor is greater than the random number the configuration is kept, but if the Boltzmann factor is less than the random number the configuration is destroyed. A snapshot of the end product after 100,000 iterations is shown in Figures $10 \& 11$ for methane and carbon dioxide.



Figure 10. Representation of the Pocahontas No. 3 coal molecular model with appropriate carbon dioxide content (shown as spheres). Image is generated with a fixed loading simulation with a 2:1 molar ratio of carbon dioxide to methane. 


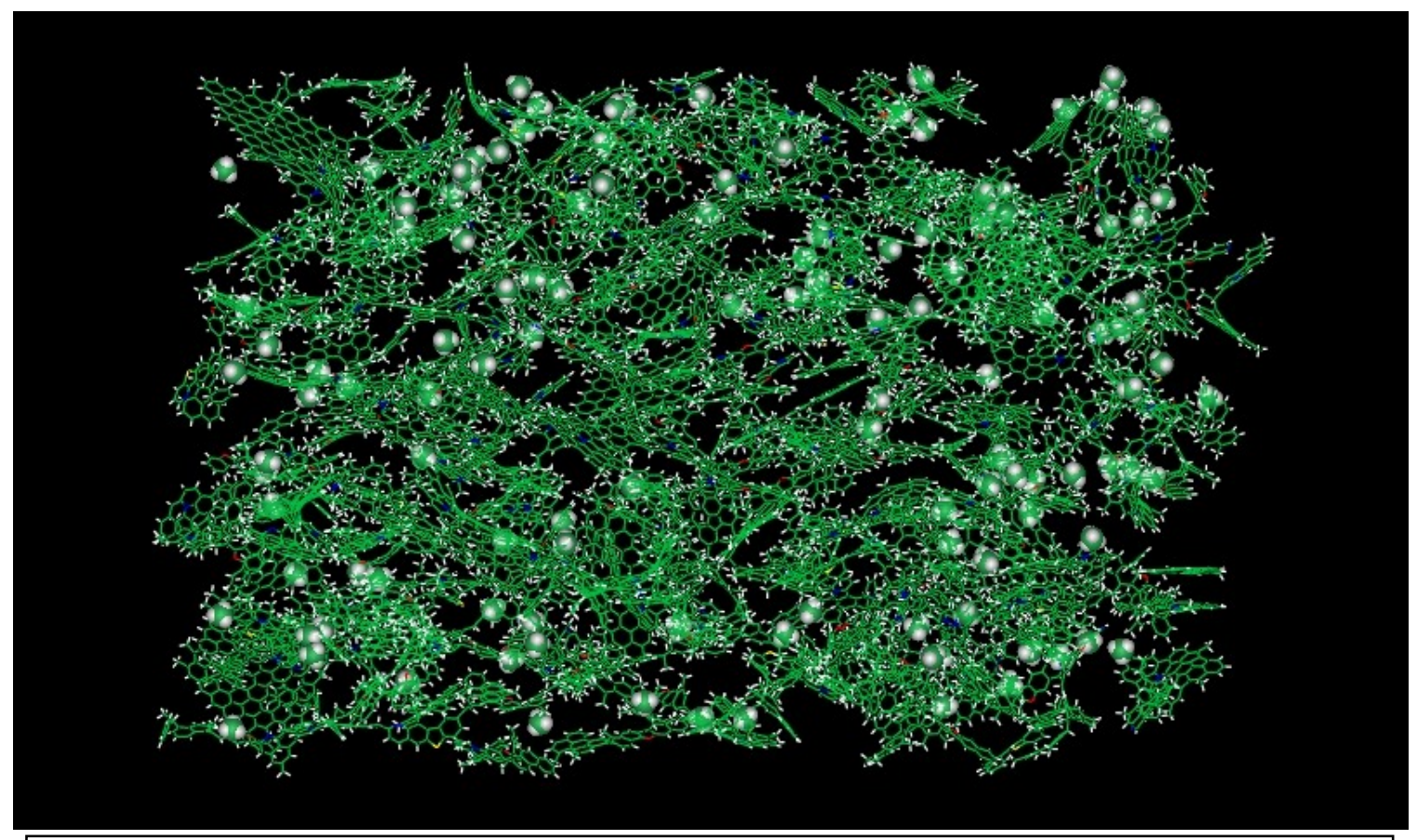

Figure 11. Representation of the Pocahontas No. 3 coal molecular model with appropriate methane content (shown as spheres). Image is generated with a fixed loading simulation.

Moisture content reduces the capacity for coal to sequester $\mathrm{CO}_{2}$. The as-received moisture for the Argonne Premium Pocahontas coal is $0.66 \%$ by mass ash-free basis. It is known that the inherent moisture associates with the oxygen within coal. Roughly half of the oxygen atoms within the structural representation will be associated with the 64 water molecules a structure of this size should contain. The water molecules were manually added randomly to those oxygen atoms with enough room to accommodate a water molecule. Following minimization the structural model was found to have swelled $1 \%$ which is in agreement with expectation. The model with water content represented is shown in Figure 12. Future work will attempt to elucidate the mechanism by which the water reduces the capacity of coal to sequester $\mathrm{CO}_{2}$. 


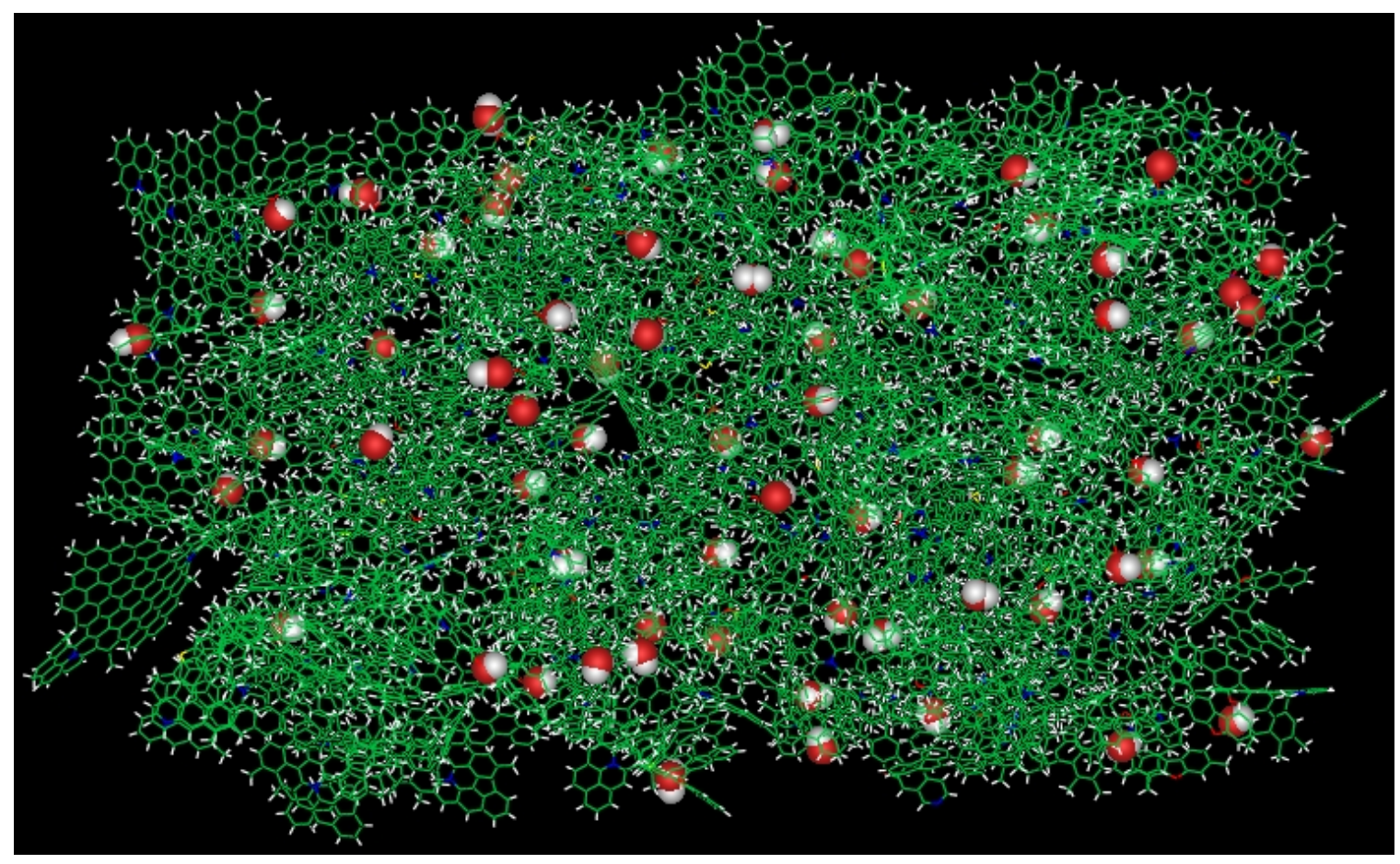

Figure 12. Representation of the Pocahontas No. 3 coal molecular model with as-received water content shown as ball configuration.

\section{CONCLUSIONS}

We are midway in completing the necessary steps to carrying out large scale molecular dynamics simulations to develop a state-of-the-art large scale structural representation of a bituminous coal of lower bituminous rank. The installation of quality $\mathrm{CO}_{2}$ parameters and the treatment of atoms in coal require a careful treatment. Preliminary structure(s) has been used to investigate the molecular forces between the bituminous coal structure (or idealized pores) and the molecular species $\mathrm{CH}_{4}$ and $\mathrm{CO}_{2}$. We have created a new force field for these simulations and are almost ready to begin carrying out molecular dynamics simulations. An initial step performed is to help define the issues with sequestration utilizing the molecular modeling approach. Once defined advanced molecular modeling techniques can be utilized in investigating sorbent and host behavior. 


\section{REFERENCES}

1. Foresman, J., Frisch, A, Exploring Chemistry with Electronic Structure Methods 2nd Ed. 2 ed. 1993, Piitsburgh: Gaussian Inc.

2. Becke, A.D., Density-functional thermochemistry. III. The role of exact exchange. Journal of Chemical Physics, 1993. 98(7): p. 5648-52.

3. Lee, C., W. Yang, and R.G. Parr, Development of the Colle-Salvetti correlation-energy formula into a functional of the electron density. Physical Review B: Condensed Matter and Materials Physics, 1988. 37(2): p. 785-9.

4. Leech, A., Molecular Modeling Principles and Applications. 2 ed. 2001, Harlow, England: Prentice Hall.

5. M. J. Frisch, G.W.T., H. B. Schlegel, G. E. Scuseria, M. A. Robb, J. R. Cheeseman, V. G. Zakrzewski, J. A. Montgomery, Jr., R. E. Stratmann, J. C. Burant, S. Dapprich, J. M. Millam, A. D. Daniels, K. N. Kudin, M. C. Strain, O. Farkas, J. Tomasi, V. Barone, M. Cossi, R. Cammi, B. Mennucci, C. Pomelli, C. Adamo, S. Clifford, J. Ochterski, G. A. Petersson, P. Y. Ayala, Q. Cui, K. Morokuma, D. K. Malick, A. D. Rabuck, K. Raghavachari, J. B. Foresman, J. Cioslowski, J. V. Ortiz, A. G. Baboul, and G.L. B. B. Stefanov, A. Liashenko, P. Piskorz, I. Komaromi, R. Gomperts, R. L. Martin, D. J. Fox, T. Keith, M. A. Al-Laham, C. Y. Peng, A. Nanayakkara, M. Challacombe, P. M. W. Gill, B. Johnson, W. Chen, M. W. Wong, J. L. Andres, C. Gonzalez, M. Head-Gordon, E. S. Replogle, and J. A. Pople, Gaussian 98, Revision A.9. 1998, Gaussian Inc.: Pittsburgh, PA.

6. M. J. Frisch, G.W.T., H. B. Schlegel, G. E. Scuseria, M. A. Robb, J. R. Cheeseman, V. G. Zakrzewski, J. A. Montgomery, Jr., R. E. Stratmann, J. C. Burant, S. Dapprich, J. M. Millam, A. D. Daniels, K. N. Kudin, M. C. Strain, O. Farkas, J. Tomasi, V. Barone, M. Cossi, R. Cammi, B. Mennucci, C. Pomelli, C. Adamo, S. Clifford, J. Ochterski, G. A. Petersson, P. Y. Ayala, Q. Cui, K. Morokuma, D. K. Malick, A. D. Rabuck, K. Raghavachari, J. B. Foresman, J. Cioslowski, J. V. Ortiz, A. G. Baboul, and G.L. B. B. Stefanov, A. Liashenko, P. Piskorz, I. Komaromi, R. Gomperts, R. L. Martin, D. J. Fox, T. Keith, M. A. Al-Laham, C. Y. Peng, A. Nanayakkara, M. Challacombe, P. M. W. Gill, B. Johnson, W. Chen, M. W. Wong, J. L. Andres, C. Gonzalez, M. Head-Gordon, E. S. Replogle, and J. A. Pople, Gaussian 03, Revision B.03. 2003, Gaussian Inc.: Pittsburgh, PA.

7. Sadlej, J., Makarewicz, J., Chalasinski, G., Ab Initio study of energy, structure and dynamics of the water-carbon dioxide complex. J. Chem Phys., 1998. 109(10): p. 3919.

8. Becker, O.B., et al., Computational Biochemistry and Biophysics. 2001, New York: Marcel Dekker, Inc.

9. Jorgensen, W., BOSS. 2002, Yale University: New Haven.

10. Field, M., A Practical Intoduction To The Simulation Of Molecular Systems. 1999, Cambridge: Cambridge University Press.

11. Jorgensen, W.L., Quantum and statistical mechanical studies of liquids. 10. Transferable intermolecular potential functions for water, alcohols, and ethers. Application to liquid water. Journal of the American Chemical Society, 1981. 103(2): p. 335-40.

12. Jorgensen, W.L., et al., Comparison of simple potential functions for simulating liquid water. Journal of Chemical Physics, 1983. 79(2): p. 926-35.

13. Murthy, C., Singer, K., McDonald, I., Interaction site models for carbon dioxide. Molecular Physics, 1981. 44(1): p. 135.

14. Steele, W., Birnbaum, G., Molecular calculations of moments of the induced spectra for $\mathrm{N}_{2}, \mathrm{O}_{2}$, and $\mathrm{CO}_{2}$. J. Chem Phys., 1980. 72(4): p. 2250. 
15. Harris, J., Yung, K., Carbon Dioxide's Liquid-Vapor Coexistence Curve and Critical Properties As Predicted by a Simple Molecular Model. J. Chem. Phys., 1995. 99(31): p. 12021-12024.

16. Peterson, K., Klemperer, W., Structure and internal rotation of $\mathrm{H}_{2} \mathrm{O}-\mathrm{CO}_{2}, \mathrm{HDO}-\mathrm{CO}_{2}$, and $\mathrm{D}_{2} \mathrm{O}-$ $\mathrm{CO}_{2}$ van der Waals complexes. J. Chem Phys., 1984. 80(6): p. 2439.

\section{BIBLIOGRAPHY}

Dick, T. J., Acevedo, O., Dalal, P., Madura, J. D., Evanseck, J. D. and Mathews, J. P., Molecular Basis for Carbon Dioxide Sequestration in Coal, Am. Chem. Soc. Div. Fuel Chem. Prepr., 2002, Orlando, Fl, April 7-11, Online at:

http://pubs.acs.org/meetingpreprints/, 47 (1), 14.

Mathews, J. P., Halleck, P., Narkiewicz, M. R. and Hile, M., PRESENTATION: "CO 2 sequestration within Coal", North American Coalbed Methane Forum, Washington, PA, 2005, Presented 13th of April, 2005,

Mathews, J. P., Halleck, P., Narkiewicz, M. R. and Hile, M., PRESENTATION: "CO sequestration within Northern Hemisphere Coal", Fossil Fuel Foundation of South Africa, 2005, Johannesburg Country Club, Presented 4th of April, 2005,

Mathews, J. P. and Narkiewicz, M. R., Visualization and quantification of carbon dioxide sequestration issues within coal using a molecular representation of Pocahontas No.3 coal, International Conference on Coal Science and Technology, 2005, Okinawa, Japan, abstract accepted.

The role of hydrogen bonding at interfaces. Madura, Jeffry D. Abstracts of Papers, 229th ACS National Meeting, San Diego, CA, United States, March 13-17, 2005 (2005), PHYS-109.

Studies of brine using TIP4P-Ew and DYNAMO. Krouskop, Peter E.; Madura, Jeffry D. Abstracts of Papers, 228th ACS National Meeting, Philadelphia, PA, United States, August 22-26, 2004 (2004), COMP-201.

Development of an improved four-site water model for bio-molecular simulations: TIP4P-Ew. Horn, Hans W.; Swope, William; Pitera, Jed; Madura, Jeffry D.; Dick, Thomas J.; Hura, Greg L. B.; Head-Gordon, Teresa. Abstracts of Papers, 228th ACS National Meeting, Philadelphia, PA, United States, August 22-26, 2004 (2004), COMP-200.

Development of an improved four-site water model for biomolecular simulations: TIP4P-Ew. Horn, Hans W.; Swope, William C.; Pitera, Jed W.; Madura, Jeffry D.; Dick, Thomas J.; Hura, Greg L.; Head-Gordon, Teresa. Journal of Chemical Physics (2004), 120(20), 9665-9678.

A Review of the TIP4P, TIP4P-Ew, TIP5P, and TIP5P-E Water Models. Dick, T. J.; Madura, Jeffry D. Annual Reports in Computational Chemistry, 2005, volume 1, 59-74. 


\section{LIST OF ACRONYMS AND ABBREVIATIONS}

CCSD coupled clusters with single and double excitations

DFT density functional theory

HF Hartree-Fock

HRTEM high-resolution transmission electron microscopy

MC Monte Carlo

MM Molecular Mechanical

MPPT Möller-Plesset perturbation theory

QM Quantum Mechanical

TJDM1 Tom Jeffry David Madura 1 water model 